\title{
Student Perception of Microbiology Laboratory Skills Learning Through a Problem-Based Learning Curriculum: Arabian Gulf University Experience
}

This article was published in the following Dove Press journal:

Advances in Medical Education and Practice

\section{Khalid Mubarak Bindayna \\ Ahmed Qareeballa \\ Ronni Mol Joji \\ Ali Al Mahmeed \\ Hicham Ezzat \\ Abdulrahman Yousif Ismaeel (ID \\ Khaled S Tabbara}

Microbiology, Immunology and Infectious Diseases Department, College of Medicine and Medical Sciences, Arabian Gulf University, Manama, Kingdom of Bahrain
Correspondence: Khalid Mubarak Bindayna Microbiology, Immunology, and Infectious Diseases Department, College of Medicine and Medical Sciences, Arabian Gulf University, Manama, Kingdom of Bahrain

Email bindayna@agu.edu.bh
Introduction: The curriculum at medical school at Arabian Gulf University is centered on small group learning and real-life problems provided to students and guiding students to learn actively. In microbiology, laboratory skills are taught in an innovative manner using mini cases and different lab sessions and are integrated with other basic sciences. This article describes the format and pattern of laboratory skills sessions conducted using PBL methods at Arabian Gulf University and discusses the perception of students towards PBL in laboratory skill learning and way forward for the same.

Methods: The study sample size was 110 . The students' perception of the laboratory skills teaching methods was assessed through an exit survey at the end of each session. A semistructured self-administered survey instrument was prepared, and the questions were arranged in two sessions and focused on identifying the relevance, timing, strengths, and weaknesses of the teaching method and recommendations to improve the same.

Results: We observed that more than $50 \%$ of the participants agreed or strongly agreed that the time given for PBL was adequate, topics discussed were relevant, presentations were clear, pre-session briefing and Case-Based Studies (team-based learning (TBL)) helped in their learning. The participants identified the demonstration of experiments and hands-on experience provided in the laboratory were most helpful. When enquired about the difficulty, among $48 \%$ of the participants, $80 \%$ observed that the slides used in the learning/teaching were lengthy.

Conclusion: The use of PBL in a lab setting promotes active learning. In the heart of PBL, TBL is a powerful tool in the educational process offering the students deep comprehension and allowing them to gain practical and intellectual skills.

Keywords: PBL, microbiology, laboratory skill learning

\section{Introduction}

Traditionally, microbiology laboratory skill is taught to students using a pre-defined manual that outlines the steps and procedures to be followed and the results to be expected at the end of the experiment together with a logbook. ${ }^{1}$ This often ignores the importance of applying the concepts of science in the real-world situation. In the real world, we may need to work in reverse order from the problem to the solution as doctors are provided with problems/questions and they need to find their way around to the answers and solutions. These shortcomings are overcome in Problem Based Learning (PBL). Problem-based learning turns the learning from passive to an active process. In PBL, students are inspired and motivated to learn through 
challenges in a stimulating environment. In PBL, students are guided and trained to think critically about a problem with team members and arrive at reliable solutions. ${ }^{2}$ The PBL sessions enable students to prepare for their application/lab sessions in an active and interactive manner through pre-laboratory activities. By incorporating elements of group work, debate, hands-on experiences and alternative evaluation approaches, students are presented with an atmosphere conducive to meaningful, profound learning. ${ }^{3}$ Studies have reported the effectiveness of PBL in demonstrating its superior efficacy in the long-term retention of information and in the knowledge application. ${ }^{4}$ Arabian Gulf University (AGU) is a multinational university established in 1983. The university aims to promote education and research in the Gulf Region. The institute has adopted the Problem Based Learning (PBL) approach since its inception. The principles and practice of medicine are taught/learnt through a series of problems that are drafted to address both the clinical and population health needs and consider both the local and global scenarios. ${ }^{5}$ The curriculum is crafted to provide a stimulating student-centred, self-directed, community-oriented learning environment and to inculcate life-long learning habits in students. The undergraduate curriculum spans over 6 years and is split into 3 phases. The first phase consists of a basic introductory course that will sensitize and prepare students for medical education. The second phase is the main pre-clerkship period and lasts for a period of 3 years. The third phase is the clerkship phase and is for another two years. Students are introduced to both theoretical and practical aspects of medicine through various innovative and diverse activities. The program's curriculum is achieved by multiple activities and some additional programs. Practical, professional and intellectual skills program ${ }^{6}$ conducted at the university is primarily based on clinical reasoning and communication skills. It links and reinforces the concepts learned through the problems presented every week. At AGU, the philosophy of PBL is extended in learning/teaching laboratory skills. The general objectives of PBL in laboratory skills are defined in line with the objectives of the overall curriculum at the institute and are as follows: active learning through real-life case scenarios, introduction of laboratory techniques through innovative teambased techniques, exploration of meaningful learning by examining microbiological aspects of common diseases through laboratory means, and integration of previous knowledge and application of this information in active learning. Specific deliverables of the lab sessions are students' ability to demonstrate pre-specified laboratory skills relevant and important in the diagnosis of common health problems, recognize and characterize common pathogenic microorganisms, and analyse and interpret laboratory data and correlate the lab tests with clinical histories. To achieve these goals, a series of problems and experiments help the students to go through the entire set of laboratory skills. The laboratory sessions provide students an opportunity to revisit the subject under study in another platform through observation, identification, and interpretation. Demonstration of microbiological procedures through live demonstrations, videos, mini-case studies, and critical thinking which, are facilitated by a tutor, forms the core of teaching and learning. The laboratory provides a platform where the knowledge and skills that are acquired can be put to practice in real-life scenarios all the way fostering enquiry-based learning and hands on training. This article describes the format and pattern of laboratory skills sessions conducted using PBL methods at Arabian Gulf University and discusses the perception of students towards PBL in laboratory skills learning and way forward for the same.

\section{Methods}

\section{Construction of Laboratory Curriculum}

Students are divided into smaller subgroups (10 students randomly chosen) to encourage individual participation. Each session is conducted twice and is facilitated by an instructor/technologist and is supervised by a faculty member. Three to four stations are displayed for the student in each session. The laboratory coordinator briefs the class about the problem under study and tutors the class at the beginning of each session. The students are provided with a set of objectives to be achieved at the end of each station (Appendix 1). Students rotate through these stations and work in groups to achieve the objectives based on their previous knowledge, resource lectures, briefing, and brainstorming. In Case-based studies, to foster groupbased/team learning, clinical cases are designed based on real-life scenarios and are presented to the students into sequential vignettes. The content of the cases is as per the curricular phase and addressing the community/society level health issues. Each session introduces students to three cases. The class is briefed about all the cases under study through active discussion at the beginning of the session. Students are then divided into three working 
groups/teams (10 -15 students in each group) and a different case is allotted to each group. Discussions and brainstorming within the group are facilitated by a faculty member who monitors and guides the students. Students identify the problems, device solutions and microbiological examinations needed to solve the cases. This is followed by the reconvening of the group. A representative from each group will present the case and their learning to others. This will be followed by further discussion and question and answer sessions with the class (Appendix 2). These sessions are purposely designed to complement resource sessions and permit the student to apply theoretical concepts, enhance their cognitive and technical skills and to develop expertise in problem-solving and data analysis (Figure 1) in the evidence-based medicine concept. ${ }^{7}$ Lastly, the laboratory also provides microscopy, bench sheets (ie, life cycles of a parasite), video monitor microscope, culture plates, stained slides, etc. to introduce and facilitate learning/teaching various microbiological concepts by students.

\section{Student Assessment Method}

Evaluation of student's learning and performance is considered to be the most challenging part of PBL and has an important impact on their learning. ${ }^{8,9}$ At AGU laboratory skills are assessed using Objective Structured Practical Examination (OSPE). OSPE is an assessment method that is developed to overcome the shortcomings of traditional examinations based on clinical cases. OSPE assesses the student in various components including history taking, physical examination, simple procedures, interpretation of lab results, patient management problems, communication, attitude, etc. are tested using agreed checklists and rotating the student round several stations. ${ }^{10}$ The OSPE covers a broad range of skills compared to conventional exams. The examination is objective and overcomes the variation seen and biases seen in the traditional exam. In OSPE teaching and evaluation are integrated and are interactive in nature. ${ }^{10}$ OSPE is time and resource-effective and helps in achieving better outcomes.

\section{Student Perception Survey}

The students' perception of the laboratory skills teaching methods is assessed through an exit survey at the end of each session. A semi-structured self-administered survey instrument (Appendix 3) was prepared in line with the objective of the study. The tool was pilot tested with ten
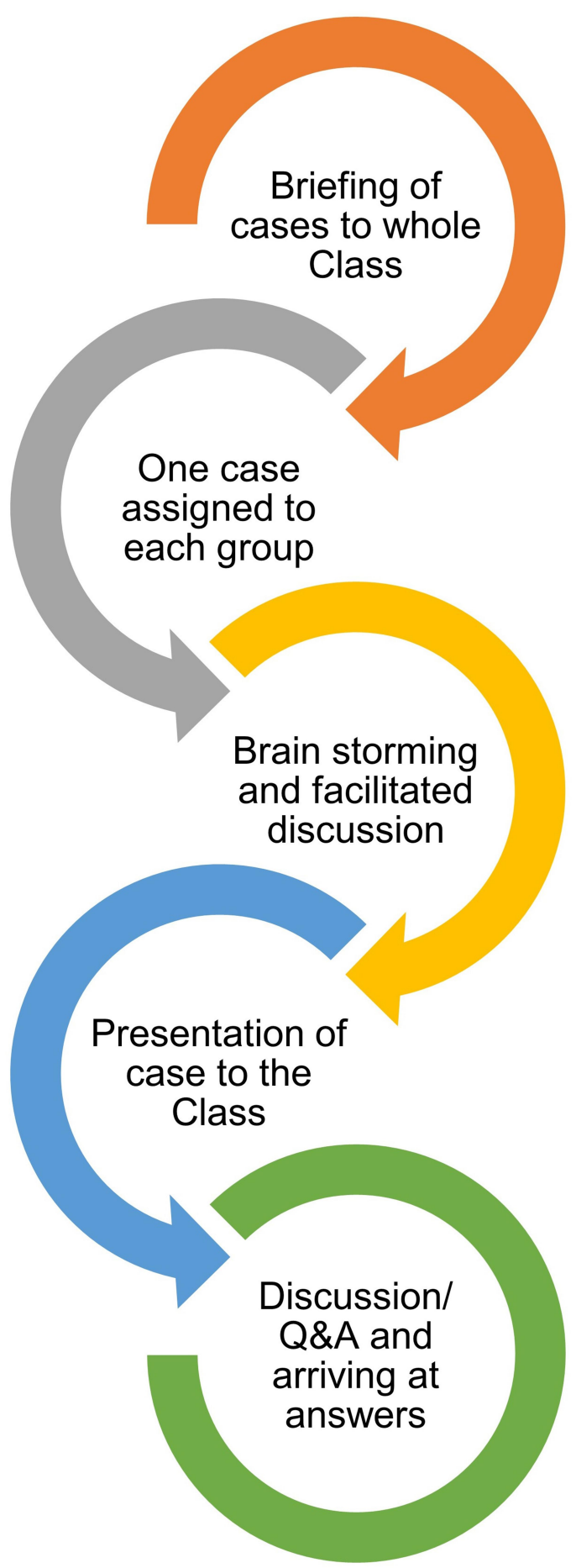

Figure I Mini-Case Learning Format.

students before finalizing. The questions were arranged in two sessions and focused on identifying the relevance, timing, strengths, and weaknesses of the teaching method and recommendations to improve the same. We used convenient sampling and included all the students attending a certain laboratory session for the survey. Students who did not consent were excluded from the survey. The total 
sample size for the study was 110. Approval from the Institutional Ethics Committee and the informed consent from each participant were obtained for the conduction of the study. Our research study complies with the Declaration of Helsinki.

\section{Results}

Thirty-six percentage (36\%) of the participants belonged to the 2nd year unit I

\& II, $29 \%$ were in 3 rd year unit IV \& V, 35\% were in 4th year Unit VII \& VIII (all students were in Phase 2, Figure 2). We used the Likert scale to assess the perception of students about different aspects of PBL in laboratory. We observed that more than $50 \%$ of the participants agreed or strongly agreed that the time given for PBL is adequate, topics discussed in PBL sessions are relevant, presentations were clear, pre-session briefing helped and CaseBased Studies (team based learning, TBL) helped in their learning (Table 1). When enquired about the most helpful part of the session, the factors identified as helpful in the descending order of frequency are the demonstration of experiments and hands-on experience provided in the laboratory, pre- and post-session discussions, guidance of the tutors and handouts and the reference materials provided. We also enquired about the difficulties faced by the students during the session. The response rate for the question was only $48 \%$ (Table 1 ). Of these, more than $80 \%$ mentioned that the slides used in the learning/teaching were lengthy and it needs to be reduced as it is difficult for students to retain so much information. One of the suggestions provided in this regard is to include only important aspects of the slides. The second most mentioned difficulty is about the equipment in the laboratory. Students suggested that the microscopes should be

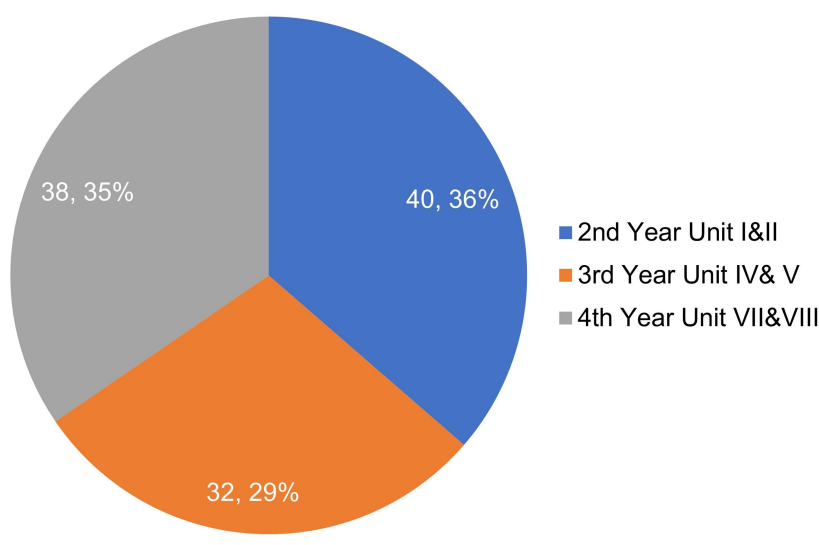

Figure 2 Distribution of Participants. updated. Other suggestions given by the students are about allotting a different time slot for interacting with the tutor and arranging the lecture and the hands-on practice on the same day with a rather blended approach. The student's perception will be addressed to improve the curriculum by emphasizing on the quality of the learning/teaching process in the sessions.

\section{Discussion}

Laboratories constitute a stimulating environment to develop practical skills. ${ }^{11}$ The use of different techniques into the lab session seems to be appreciated by our students combining visual effects and discussion were perceived positively by our students in accordance to previously published articles. ${ }^{11-15}$ The medical students' perception of laboratory learning is critical considering the stress and depression they are experiencing. ${ }^{16,17}$ Lab skills in most traditional medical schools use certain practical classes in which the students understand a concept using microscopy, laboratory procedures or lab manuals. In other schools, students are given a guidebook with the lab procedures described and students are asked to merely follow, then to memorize them. ${ }^{1,18}$ Both the traditional and PBL students cover the techniques and the concepts within the specified period and by using similar resources. However, the PBL approach, gives more opportunity for the students to develop the skills, understand the concepts and the applications. Students gain the knowledge of the whole scientific method in a relevant and stimulating environment. Additionally, they seem to enjoy the experience. ${ }^{3}$ Allen and Tanner in their article on approaches to biology teaching learning explained the importance of having a student customized approach in science. ${ }^{19}$ The group/ team-based discussions have been used in the lab sessions as they engage students in learning and encourage them to a deeper understanding and may help in the development of responsibility. ${ }^{14}$ Medical students in laboratory medicine and skills have been addressed by several investigators. The assessment of the student's perception of PBL as a medium of study has also shown varied results. It is seen to vary from acceptance through to resentment in students in some studies. ${ }^{20}$ Team-based learning (TBL) active approaches in microbiology have shown to positively influence the learning process. $^{21-24}$ The use of case scenarios allowed learners to think, visualize changes and link knowledge from several disciplines to answer challenges/tasks and justify their views. It is obvious from the students' responses to the questionnaire that they enjoyed learning in the new format. The use of case scenarios and exposing students to microbiology in relation to 
Table I Survey Response (in Percentage) to PBL Curriculum

\begin{tabular}{|l|l|l|l|l|l|}
\hline Variables & Strongly Disagree & Disagree & Cannot Comment & Agree & Strongly Agree \\
\hline Adequacy of Time & 11.8 & 16.4 & 19.1 & 27.3 & 25.5 \\
Relevance to topic under study & 8.2 & 10.0 & 23.6 & 30.9 & 27.3 \\
Clarity of teaching material & 26.4 & 14.5 & 26.4 & 10.9 & 21.8 \\
Pre session Briefing & 10.0 & 16.4 & 18.2 & 31.8 & 23.6 \\
Relevance to clinical diagnosis & 4.5 & 10.9 & 27.3 & 31.8 & 25.5 \\
Clarity of Presentation & 18.2 & 12.7 & 20.0 & 27.3 & 21.8 \\
Observation before session & 13.6 & 16.4 & 29.1 & 19.1 & 21.8 \\
Usefulness of CBS & 8.2 & 15.5 & 22.7 & 30.9 & 22.7 \\
\hline
\end{tabular}

these scenarios allowed students to put different pieces of knowledge together, justify their views, and apply knowledge learnt to real-life situations. Our students suggested a flexible time format with prior indulgent start and intra/inter team discussions during the lab sessions rather in a blended manner in agreement with previous-published preferences. ${ }^{14,15}$ Our survey also showed that the students find PBL components to be useful. The survey responses also served as an internal trigger for quality improvement. It provided us with directions for optimizing our system and to strive for better outcomes. In summary, the use of PBL in a lab setting promotes active learning. In the heart of PBL, TBL is a powerful tool to centre the students in the educational process offering them deep comprehension and allowing them to gain practical and intellectual skills. In fact, when amalgamated with the case-based scenarios, practical sessions enhance student understanding and help to improve student outcomes.

\section{Disclosure}

The authors declare no potential conflicts of interest in this work.

\section{References}

1. Matsuo O, Takahashi Y, Abe C, Tanaka K, Nakashima A, Morita H. Trial of integrated laboratory practice. Adv Physiol Educ. 2011;35 (2):237-240. doi:10.1152/advan.00047.2010

2. Neville AJ, Norman GR. PBL in the undergraduate MD program at McMaster University: three iterations in three decades. Acad Med. 2007;82(4):370-374. doi:10.1097/ACM.0b013e318033385d

3. Kelly OC, Finlayson OE. Providing solutions through problem-based learning for the undergraduate 1st year chemistry laboratory. Chem Educ Res Pract. 2007;8(3):347-361. doi:10.1039/B7RP90009K

4. Yew EHJ, Goh K. Problem-based learning: an overview of its process and impact on learning. Health Prof Educ. 2016;2(2):75-79. doi:10.1016/j.hpe.2016.01.004

5. Hamdy H, Anderson MB. The Arabian Gulf University College of medicine and medical sciences: a successful model of a multinational medical school. Acad Med. 2006;81(12):1085-1090. doi:10.1097/01. ACM.0000246680.82786.76
6. Hamdy H, Greally M, Grant IN, et al. Professional skills programme in a problem-based learning curriculum: experience at the College of Medicine \& Medical Sciences, Arabian Gulf University. Med Teach. 2001;23(2):214-216. doi:10.1080/014215901750177604

7. Hunt DP, Haidet P, Coverdale JH, Richards B. The effect of using team learning in an evidence-based medicine course for medical students. Teach Learn Med. 2003;15(2):131-139. doi:10.1207/ S15328015TLM1502_11

8. Lipnevich AA, Smith JK Listening. Learning. Leading. ${ }^{\circledR}$ Response to assessment feedback: the effects of grades, praise, and source of information; 2008. Available from: http://www.ets.org/research/con tact.html. Accessed March 22, 2020.

9. Savin-Baden M. Understanding the impact of assessment on students in problem-based learning. Innov Educ Teach Int. 2004;41 (2):221-233. doi:10.1080/1470329042000208729

10. Ananthakrishnan N. Objective structured clinical/practical examination (OSCE/OSPE). J Postgraduate Med. 1993;39(2):82-84.

11. Brockman RM, Taylor JM, Segars LW, Selke V, Taylor TAH. Student perceptions of online and in-person microbiology laboratory experiences in undergraduate medical education. Med Educ Online. 2020;25(1):1710324. doi:10.1080/10872981.2019.1710324

12. Blewett EL, Kisamore JL. Evaluation of an interactive, case-based review session in teaching medical microbiology. BMC Med Educ. 2009;9:56. doi:10.1186/1472-6920-9-56

13. Braun MW, Kearns KD. Improved learning efficiency and increased student collaboration through use of virtual microscopy in the teaching of human pathology. Anat Sci Educ. 2008;1(6):240-246. doi: $10.1002 /$ ase. 53

14. Burgess A, Ayton T, Mellis C. Implementation of team-based learning in year 1 of a PBL based medical program: a pilot study. $B M C$ Med Educ. 2016;16:49. doi:10.1186/s12909-016-0550-3

15. Salter S, Gardner C. Online or face-to-face microbiology laboratory sessions? First year higher education student perspectives and preferences. Creative Educ. 2016;7:1869-1880. doi:10.4236/ ce.2016.714189

16. Kotter T, Wagner J, Bruheim L, Voltmer E. Perceived medical school stress of undergraduate medical students predicts academic performance: an observational study. BMC Med Educ. 2017;17(1):256. doi:10.1186/s12909-017-1091-0

17. Puthran R, Zhang MW, Tam WW, Ho RC. Prevalence of depression amongst medical students: a meta-analysis. Med Educ. 2016;50 (4):456-468. doi:10.1111/medu.12962

18. Dantas AM, Kemm RE. A blended approach to active learning in a physiology laboratory-based subject facilitated by an e-learning component. Adv Physiol Educ. 2008;32(1):65-75. doi:10.1152/ advan.00006.2007

19. Tanner K, Allen D. Approaches to biology teaching and learning: learning styles and the problem of instructional selection-engaging all students in science courses. Cell Biol Educ. 2004;3(4):197-201. doi:10.1187/cbe.04-07-0050 
20. Pepper C. Problem based learning in science. Issues Educ Res. 2009;19(2):128-141.

21. Trempy JE, Skinner MM, Siebold WA. Learning microbiology through cooperation: designing cooperative learning activities that promote interdependence, interaction, and accountability. Microbiol Educ. 2002;3:26-36.

22. Hoffman EA. Successful application of active learning techniques to introductory microbiology. Microbiol Educ. 2001;2:5-11.
23. Buxeda RJ, Moore DA. Transforming a sequence of microbiology courses using student profile data. Microbiol Educ. 2000;1:1-6.

24. Azer SA, Hasanato R, Al-Nassar S, Somily A, AlSaadi MM. Introducing integrated laboratory classes in a PBL curriculum: impact on student's learning and satisfaction. BMC Med Educ. 2013;13:71. doi:10.1186/1472-6920-13-71

\section{Publish your work in this journal}

Advances in Medical Education and Practice is an international, peerreviewed, open access journal that aims to present and publish research on Medical Education covering medical, dental, nursing and allied health care professional education. The journal covers undergraduate education, postgraduate training and continuing medical education including emerging trends and innovative models linking education, research, and health care services. The manuscript management system is completely online and includes a very quick and fair peer-review system. Visit http://www.dovepress.com/testimonials.php to read real quotes from published authors. 